Research Article

\title{
Calculation of Silo Wall Pressure considering the Intermediate Stress Effect
}

\author{
Shanshan Sun $\mathbb{D}$, Junhai Zhao $\mathbb{D}$, and Changguang Zhang $\mathbb{D}$ \\ School of Civil Engineering, Chang'an University, Xi'an 710061, China \\ Correspondence should be addressed to Changguang Zhang; zcg1016@163.com
}

Received 11 February 2018; Revised 4 June 2018; Accepted 27 August 2018; Published 18 September 2018

Academic Editor: Pier Paolo Rossi

Copyright (C) 2018 Shanshan Sun et al. This is an open access article distributed under the Creative Commons Attribution License, which permits unrestricted use, distribution, and reproduction in any medium, provided the original work is properly cited.

\begin{abstract}
The reasonable determination of wall pressure is critical for the design of silo structures. In this study, the primary objective is to present four novel wall pressure coefficients based on four true triaxial strength criteria in the quasiplane strain state. These four strength criteria are the Drucker-Prager (D-P) criterion, the Matsuoka-Nakai (M-N) criterion, the Lade-Duncan (L-D) criterion, and the unified strength theory (UST), and they all consider the effect of the intermediate stress yet to different extent. These coefficients have a wide application range and are readily used to predict the distribution of wall pressure for deep and squat silos. Comprehensive comparisons are made between the predictions from the wall pressure coefficients described herein and experimental data reported in the literature as well as the results from the European, American, and Chinese silo standards or the Rankine and the modified Coulomb theories. It is found that the effect of the intermediate stress on the wall pressure is very significant for both deep and squat silos; the wall pressure of the D-P criterion is underestimated, whereas that of the MohrCoulomb (M-C) criterion is overestimated; the L-D criterion is recommended to be adopted to calculate the soil wall pressure.
\end{abstract}

\section{Introduction}

Silos are widely used for the storage, handling, and transportation of bulk solids in industries. Since Janssen's proposition in 1895 [1], silo behavior has been extensively studied in terms of wall pressure and flow for different situations such as filling, storage, and discharge. Various research methods including the theoretical analysis [2-6], experimental investigation [7-14], and numerical simulation [15-20] have been used. Although much progress has been made, some aspects of the silo structural design still lack generally accepted directives [21-23].

The static pressure during the filling and storage constitutes the primary load acting on the silo wall. There are several classical theories to predict static wall pressures [24-26]. Earlier studies have shown that the wall pressure during the filling and storage can be expressed as Janssen's equation. However, a consensus with regard to the wall pressure coefficient $k$ is not generally accepted.

For deep silos, most design standards are based on the Janssen theory, but each of them uses different wall pressure coefficients. The commonly used wall pressure coefficients are the Rankine active earth pressure coefficient $k=$ $(1-\sin \varphi) /(1+\sin \varphi)$ [27], the static earth pressure coefficient $k=1-\sin \varphi$ [28], the modified static earth pressure coefficient, and the wall pressure coefficient considering wall friction [29-31]. The classical theories of wall pressure for squat silos include the Rankine theory and the modified Coulomb theory $[32,33]$. These two theories are based on the Mohr-Coulomb (M-C) criterion without considering the intermediate principal stress.

In fact, the materials stored in silos are in a quasiplane strain state where three-dimensional unequal stresses exist. As the influence of the intermediate principal stress on the material strength is in general significant, the $\mathrm{M}-\mathrm{C}$ criterion is not appropriate to predict such strength. The silo wall pressure using the $\mathrm{M}-\mathrm{C}$ criterion is then overestimated leading to a conservative silo design [34-38]. Consequently, choosing an appropriate true triaxial strength criterion, such as the Drucker-Prager (D-P) criterion, the Matsuoka-Nakai (M-N) criterion, the Lade-Duncan (L-D) criterion, or the unified strength theory (UST) can not only improve silo quality and durability but also generate economic benefits. 
In this study, the D-P criterion, the M-N criterion, the L-D criterion, and the UST are adopted to derive four novel wall pressure coefficients in quasiplane strain to consider the intermediate stress effect. The applicability condition for these coefficients is also provided. Furthermore, these coefficients are used to calculate the wall pressure for deep and squat silos. Finally, the calculated results are compared with several sets of experimental data and different standards or theories.

\section{Principles and Basic Assumptions}

2.1. Principles. The distribution of wall pressure depends on the silo type. According to the load characteristics, silos are usually divided into deep silos and squat silos. These two types of silos have different calculation methods [27].

For a deep silo $(H / D \geq 1.5$, where $H$ is the silo height and $D$ is the silo diameter), as shown in Figure 1, the wall pressure $P_{\mathrm{h}}$ on the silo wall [6] is written as

$$
P_{\mathrm{h}}=\frac{C_{\mathrm{h}} \gamma \rho\left(1-e^{-\mu k s / \rho}\right)}{\mu},
$$

where $C_{\mathrm{h}}$ is the correction factor related to the calculated height and can be determined by GB50077-2003 [27], $\gamma$ is the gravity density of bulk solids, $\rho$ is the hydraulic radius of the net horizontal cross section, $\mu$ is the friction coefficient between the silo wall and bulk solids, $k$ is the wall pressure coefficient, and $s$ is the depth from the material top or from the center of cone gravity to the calculation section.

For a squat silo $(H / D<1.5)$, the wall pressure $P_{\mathrm{h}}[6]$ is expressed as

$$
P_{\mathrm{h}}=k \gamma s .
$$

When the Rankine theory is used, the wall pressure coefficient $k$ is

$$
k=\frac{1-\sin \varphi}{1+\sin \varphi}
$$

When the modified Coulomb theory is used, the wall pressure coefficient $k$ is

$$
k=\frac{\cos ^{2} \varphi}{1+\sqrt{\sin (\varphi+\delta) / \cos \delta}}
$$

where $\varphi$ is the internal friction angle of bulk solids and $\delta$ is the wall friction angle.

It can be seen from Equations (1) and (2) that the key to calculate the wall pressure for both deep and squat silos is how to rationally determine the wall pressure coefficient $k$. In addition, bulk solids are similar to granular materials. Therefore, the wall pressure coefficient $k$ in the quasiplane strain state can be determined from the analogy with the lateral earth pressure for sandy soils acting on retaining walls.

\subsection{Basic Assumptions}

(1) The calculation of silo wall pressure can be regarded as a quasiplane strain problem [6]. The intermediate

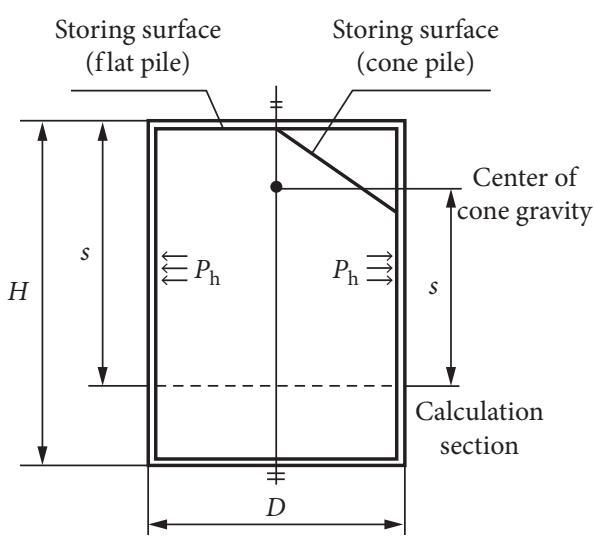

FIgURE 1: Mechanical model of silo wall pressure (no-funnel) (modified from Sun et al. [37]).

stress in bulk solids could be considered approximately as the intermediate principal stress $\sigma_{2}$ equal to the average value of the maximum principal stress $\sigma_{1}$ and the minor principal stress $\sigma_{3}$ without significant error [34-38]. This correlation is written as

$$
\sigma_{2}=\frac{1}{2}\left(\sigma_{1}+\sigma_{3}\right)
$$

(2) Bulk solids can be analogous to sandy soils. That is to say, the cohesion $c$ of bulk solids is negligible, i.e., $c=0$.

(3) The compressive stress is assumed to be positive, and the tensile stress is thus negative.

\section{Novel Wall Pressure Coefficients}

3.1. D-P Criterion. The D-P criterion $[39,40]$ known as the generalized Mises criterion makes the assumption that the intermediate principal stress and the minor principal stress have an identical effect on the material strength. The D-P criterion is expressed as

$$
\sqrt{J_{2}}=\frac{2 \sin \varphi}{\sqrt{3}(3-\sin \varphi)} I_{1}+\frac{6 c \cos \varphi}{\sqrt{3}(3-\sin \varphi)},
$$

where $J_{2}$ is the second invariant of stress deviation and $I_{1}$ is the first invariant of stress tensor.

$$
\begin{aligned}
& J_{2}=\frac{1}{6}\left[\left(\sigma_{1}-\sigma_{2}\right)^{2}+\left(\sigma_{2}-\sigma_{3}\right)^{2}+\left(\sigma_{3}-\sigma_{1}\right)^{2}\right], \\
& I_{1}=\sigma_{1}+\sigma_{2}+\sigma_{3} .
\end{aligned}
$$

Substituting Equations (5), (7), and (8) into Equation (6) with $c=0$, the wall pressure coefficient based on the D-P criterion (i.e., $k_{\mathrm{DP}}$ ) is obtained as

$$
k_{\mathrm{DP}}=\frac{\sigma_{3}}{\sigma_{1}}=\frac{3 \sqrt{3}-(6+\sqrt{3}) \sin \varphi}{3 \sqrt{3}+(6+\sqrt{3}) \sin \varphi} .
$$

3.2. M-NCriterion. The M-N criterion $[41,42]$ is suitable for cohesionless materials and overcomes the singularity of the $\mathrm{M}-\mathrm{C}$ criterion in a deviatoric plane as well as the condition of 
equal strength in tension and in compression of the D-P criterion. It reflects the effect of the intermediate principal stress on the material strength to a certain extent. The M-N criterion is expressed as

$$
\frac{I_{1} I_{2}}{I_{3}}=9+8 \tan ^{2} \varphi
$$

where $I_{2}$ and $I_{3}$ are the second and third invariants of stress tensor, respectively.

$$
\begin{aligned}
& I_{2}=\sigma_{1} \sigma_{2}+\sigma_{2} \sigma_{3}+\sigma_{3} \sigma_{1}, \\
& I_{3}=\sigma_{1} \sigma_{2} \sigma_{3} .
\end{aligned}
$$

Substituting Equations (5), (11), and (12) into Equation (10), the wall pressure coefficient based on the M-N criterion (i.e., $k_{\mathrm{MN}}$ ) is obtained as

$$
k_{\mathrm{MN}}=\frac{\sigma_{3}}{\sigma_{1}}=\frac{8}{3} \tan ^{2} \varphi+1-\frac{4}{3} \tan \varphi \sqrt{4 \tan ^{2} \varphi+3} .
$$

3.3. L-D Criterion. The expression of the L-D criterion $[43,44]$ is similar to the M-N criterion, but the limit locus of the former in the deviatoric plane is slightly larger than that of the latter. The L-D criterion is expressed as

$$
\frac{I_{1}^{3}}{I_{3}}=\frac{27+4 \tan ^{2} \varphi(9-7 \sin \varphi)}{(1-\sin \varphi)} .
$$

Substituting Equations (5), (8), and (12) into Equation (14), the wall pressure coefficient based on the L-D criterion (i.e., $k_{\mathrm{LD}}$ ) is obtained as

$$
\begin{aligned}
k_{\mathrm{LD}}=\frac{\sigma_{3}}{\sigma_{1}}= & 1+\frac{4 \tan \varphi}{27(1-\sin \varphi)}[2 \tan \varphi(9-7 \sin \varphi) \\
& -\sqrt{(9-7 \sin \varphi)\left[27(1-\sin \varphi)+4 \tan ^{2} \varphi(9-7 \sin \varphi)\right]} .
\end{aligned}
$$

3.4. UST. With fully considering the intermediate principal stress effect and its interval, the UST [45] covers the entire region from the lower bound to the upper bound of all convex strength criteria. The UST can thus be applied to various bulk solids with different tension-compression characteristics and is expressed as

$$
\begin{aligned}
& \frac{1-\sin \varphi}{1+\sin \varphi} \sigma_{1}-\frac{b \sigma_{2}+\sigma_{3}}{1+b}=\frac{2 c \cos \varphi}{1+\sin \varphi} \\
& \quad \text { when } \sigma_{2} \leq \frac{\sigma_{1}+\sigma_{3}}{2}-\frac{\sigma_{1}-\sigma_{3}}{2} \sin \varphi \\
& \frac{1-\sin \varphi}{(1+b)(1+\sin \varphi)}\left(\sigma_{1}+b \sigma_{2}\right)-\sigma_{3}=\frac{2 c \cos \varphi}{1+\sin \varphi}, \\
& \text { when } \sigma_{2} \geq \frac{\sigma_{1}+\sigma_{3}}{2}-\frac{\sigma_{1}-\sigma_{3}}{2} \sin \varphi
\end{aligned}
$$

where $b$ is the UST parameter which reflects the influence of the intermediate principal stress on the material strength, with the range $0 \leq b \leq 1$. In addition, there is a positive correlation between the parameter $b$ and the intermediate principal stress effect. In other words, the greater the parameter $b$, the higher the strength of bulk solids achieved, due to considering the intermediate principal stress effect. Also, $b$ is a parameter for choosing different strength criteria. For instance, the UST becomes the M-C criterion when $b=0$; the twin-shear stress criterion is obtained when $b=1$; a series of new strength criteria are set up when $0<b<1$.

From Equation (5), it is found that the quasiplane strain condition satisfies Equation (16b) for $\sin (\varphi) \geq 0$. Substituting Equation (5) into Equation (16b), the wall pressure coefficient based on the UST (i.e., $k_{\mathrm{UST}}$ ) is obtained as

$$
k_{\mathrm{UST}}=\frac{\sigma_{3}}{\sigma_{1}}=\frac{(2+b)(1-\sin \varphi)}{2+b+(2+3 b) \sin \varphi} \text {. }
$$

3.5. Applicable Conditions. Substituting Equations (9), (13), (15), and (17) into Equations (1) and (2), four novel formulations of wall pressure corresponding to four true triaxial strength criteria are presented for deep silos and squat silos, respectively. The application of these wall pressure coefficients (and thus the corresponding wall pressure formulations) is very simple and convenient.

According to the silo wall pressure theory [6], the wall pressure coefficient should be nonnegative, and thus the applicable condition is given by

$$
k_{\mathrm{i}} \geq 0, \quad \mathrm{i}=\mathrm{DP}, \mathrm{MN}, \mathrm{LD}, \mathrm{UST} .
$$

In addition, the wall pressure coefficients presented herein are only associated with the internal friction angle $\varphi$ of bulk solids. Accordingly, $\varphi$ should fulfill Equation (18), which means that $\varphi \leq 42.22^{\circ}$ for the D-P criterion, whereas the other three strength criteria impose no restrictions on $\varphi$ and therefore have a wider applicable range.

3.6. Comparisons of Wall Pressure Coefficients. Figure 2 illustrates the values of $k_{\mathrm{DP}}, k_{\mathrm{MN}}, k_{\mathrm{LD}}$, and $k_{\mathrm{UST}}(b=0,1 / 2$, and $1)$ as well as the wall pressure coefficients from the European silo standard (EN1991-4), American silo standard (ACI31397), and Chinese silo standard (GB50077-2003) for different values of the internal friction angle $\varphi$. Equation (4) of the modified Coulomb theory is not shown in Figure 2 in that the wall friction angle $\delta$ needs to be known.

From Figure 2, it can be seen that the wall pressure coefficients all decrease with increasing the internal friction angle of bulk solids, and their relative values are (from bigger to smaller) EN1991-4, ACI313-97, GB50077-2003 = the UST $(b=0)$, the UST $(b=1 / 2)$, the M-N criterion, the UST $(b=1)$, the L-D criterion, and the D-P criterion. The European silo standard using the modified static earth pressure coefficient as $1.1 \times(1-\sin \varphi)$ is the most conservative, while the American silo standard using the static earth pressure coefficient as $1-\sin \varphi$ is slightly smaller. The Chinese silo standard using the Rankine active earth pressure coefficient 


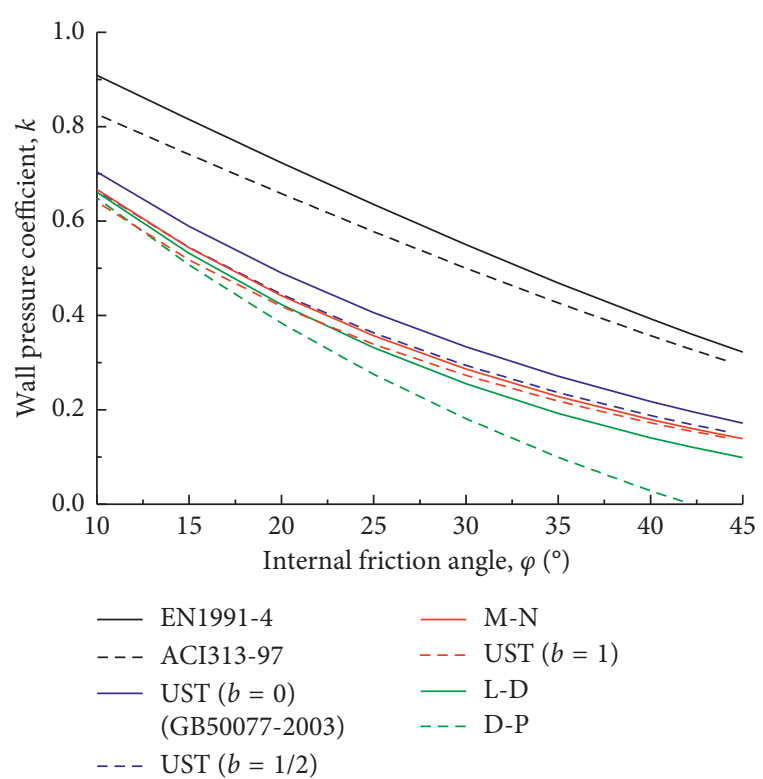

FIgURE 2: Comparisons of the wall pressure coefficient.

from the M-C criterion expressed as in Equation (3) is consistent with that of the UST when $b=0$.

Meanwhile, the wall pressure coefficients for different strength criteria have significant differences due to the different influence of the intermediate stress. The wall pressure coefficient based on the UST when $b=0$ is relatively larger due to not considering the intermediate stress effect. On the contrary, the $k_{\mathrm{DP}}$ of the D-P criterion for $\varphi \leq 42.22^{\circ}$ is the smallest due to the large influence of the intermediate stress.

\section{Comparisons and Discussions}

To demonstrate the applicability and differences of the four true triaxial strength criteria to calculate the silo wall pressure when considering different effects of the intermediate stress, the corresponding four wall pressure formulations are used for deep $(H / D \geq 1.5)$ and squat silos $(H / D<1.5)$, respectively. These formulations are compared with several sets of experimental data as well as with the results from three standards and two theories.

Note that the experimental data involved here are all specific measured values rather than mean ones.

4.1. Deep Silos. Liu and Hao [7], Zhang et al. [8], Ruiz et al. [11], and Munch-Andersen et al. [12] carried out model tests to measure the wall pressure distribution of deep silos. The ratio of silo height to its diameter is always greater than 1.5. The geometric data and material properties of the test silos are listed in Table 1.

4.1.1. Comparisons of the Results from Different Criteria. A total of six sets of experimental data are compared with the results from six strength criteria, as shown in Figure 3. These six strength criteria are the $\mathrm{D}-\mathrm{P}$ criterion, the $\mathrm{M}-\mathrm{N}$ criterion, the L-D criterion, and the UST $(b=0,1 / 2$ and 1$)$.
It can be found from Figure 3 that the differences of the wall pressure for deep silos calculated by different strength criteria are obvious. The effect of the strength criterion on the wall pressure results significant. The values of the wall pressure corresponding to six strength criteria are as follows: the UST $(b=0)>$ the UST $(b=1 / 2) \approx$ the M-N criterion $>$ the UST $(b=1)>$ the L-D criterion $>$ the D-P criterion. For the three groups of model tests from Liu and Hao [7], the average ratios of the $P_{\mathrm{h}}$ obtained with the six strength criteria to the experimental data are (from larger to smaller) 1.21, $1.10,1.07,1.03,0.97$, and 0.70 . For the model test from Zhang et al. [8], the ratios of the $P_{\mathrm{h}}$ obtained with the six strength criteria to the experimental data are (from larger to smaller) 1.32, 1.21, 1.19, 1.15, 1.09, and 0.80. For the model test from Ruiz et al. [11], the ratios of the $P_{\mathrm{h}}$ obtained with the six strength criteria to the experimental data are (from larger to smaller) $1.41,1.26,1.22,1.17,1.05$, and 0.61 . For the model test from Munch-Andersen et al. [12], the ratios of the $P_{\mathrm{h}}$ obtained with the six strength criteria to the experimental data are (from larger to smaller) 1.53, 1.45, 1.43, 1.40, 1.29, and 0.43 .

From the above analyses, we can conclude that the $P_{\mathrm{h}}$ of the L-D criterion agrees best with the experimental data; the $P_{\mathrm{h}}$ of the UST when $b=1 / 2$ is similar to that of the M-N criterion. The $P_{\mathrm{h}}$ using the UST when $b=0$ (i.e., the M-C criterion not considering the intermediate stress effect) is the largest; on the contrary, the $P_{\mathrm{h}}$ of the D-P criterion is the smallest since the intermediate stress effect is exaggeratedly considered to be the same as the minor principal stress effect.

4.1.2. Comparisons of the Results from the Standards. The six sets of experimental data for deep silos are once again compared with the results from the European, American, and Chinese silo standards, and the UST $(b=0)$ in which the intermediate stress effect is null, as well as the D-P criterion in which the effect of the intermediate stress is the greatest, as shown in Figure 4.

Figure 4 presents the changes of the wall pressure in magnitude from three standards and two strength criteria: EN1991-4 > ACI313-97 > GB50077-2003 = the UST $(b=0)$ $>$ the D-P criterion. For the three groups of model tests from Liu and Hao [7], the average ratios of the $P_{\mathrm{h}}$ calculated by the three standards and the two strength criteria to the experimental data are (from larger to smaller) 1.70, 1.61, 1.21, 1.21, and 0.70. For the model test from Zhang et al. [8], the ratios of the $P_{\mathrm{h}}$ calculated by the three standards and the two strength criteria to the experimental data are (from larger to smaller) $1.78,1.70,1.32,1.32$, and 0.80 . For the model test from Ruiz et al. [11], the ratios of the $P_{\mathrm{h}}$ calculated by the three standards and the two strength criteria to the experimental data are (from larger to smaller) 2.22, 2.05, 1.41, 1.41, and 0.61. For the model test from Munch-Andersen et al. [12], the ratios of the $P_{\mathrm{h}}$ calculated by the three standards and the two strength criteria to the experimental data are (from larger to smaller) 1.76, 1.73, 1.53, 1.53, and 0.43.

From the above results, we find that the three standards are all more conservative than the strength criterion considering the effect of the intermediate stress (i.e., the D-P 
TABLE 1: Geometrical data and material properties of deep silos.

\begin{tabular}{|c|c|c|c|c|c|c|c|c|}
\hline References & Model materials & $H(\mathrm{~mm})$ & $D(\mathrm{~mm})$ & $H / D$ & Bulk solids & $\gamma\left(\mathrm{kN} / \mathrm{m}^{3}\right)$ & $\varphi\left({ }^{\circ}\right)$ & $\mu$ \\
\hline \multirow{3}{*}{ Liu and Hao [7] } & \multirow{3}{*}{ Plexiglass } & \multirow{3}{*}{600} & \multirow{3}{*}{300} & \multirow{3}{*}{2.0} & Coal & 10 & 33 & 0.45 \\
\hline & & & & & Wheat & 8 & 28 & 0.4 \\
\hline & & & & & Dry sand & 16 & 32.5 & 0.43 \\
\hline Zhang et al. [8] & Plexiglass & 1200 & 500 & 2.4 & Standard sand & 17.4 & 31.1 & 0.43 \\
\hline Ruiz et al. [11] & Stainless steel & 2000 & 1000 & 2.0 & Wheat & 8.38 & 34.22 & 0.2 \\
\hline Munch-Andersen et al. [12] & Epoxy & 5000 & 700 & 7.14 & Dry sand & 15 & 40 & 0.67 \\
\hline
\end{tabular}

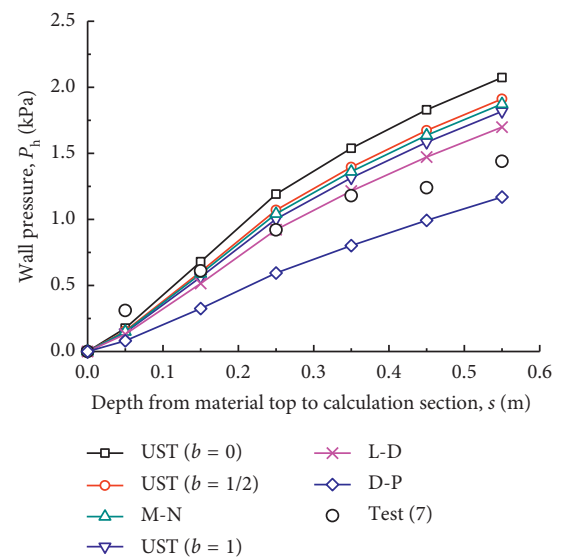

(a)

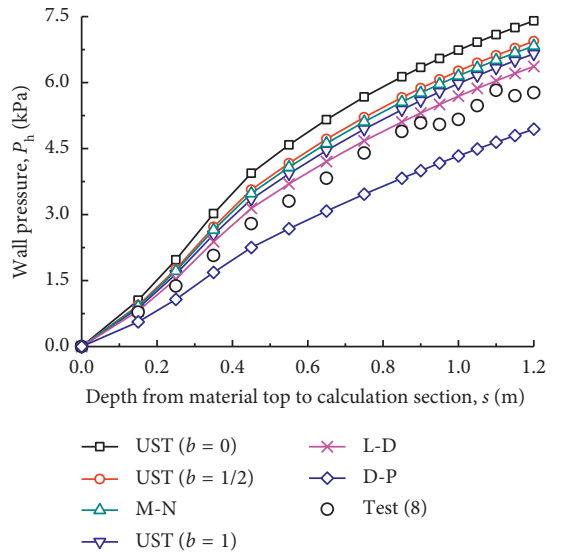

(d)

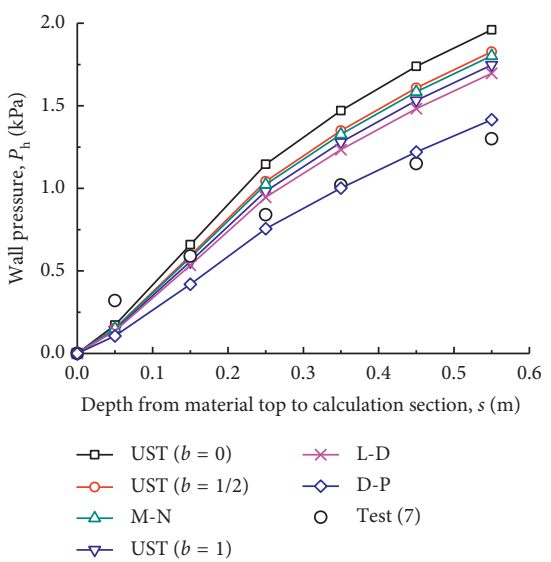

(b)

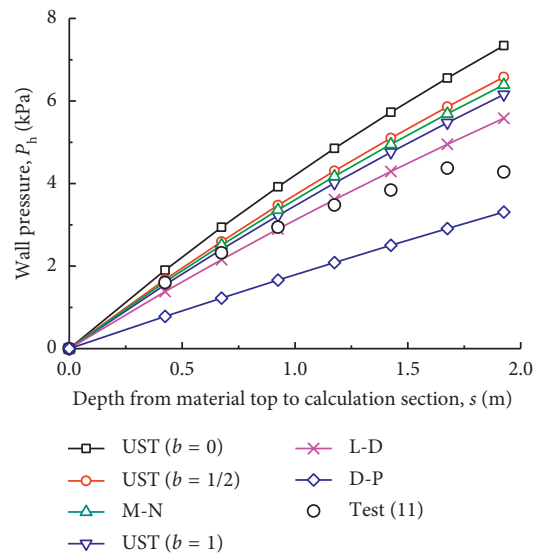

(e)

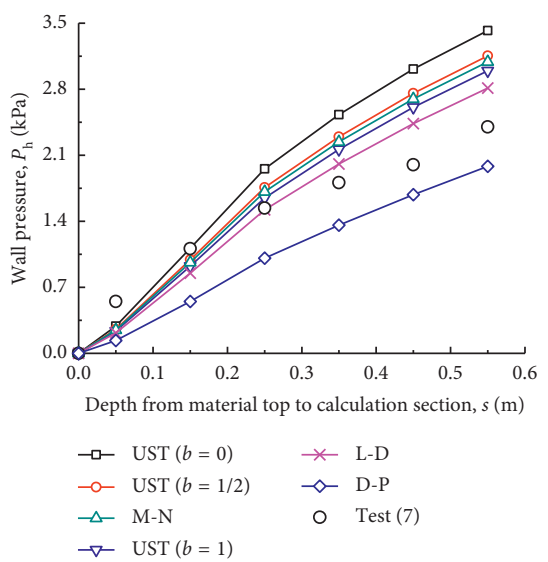

(c)

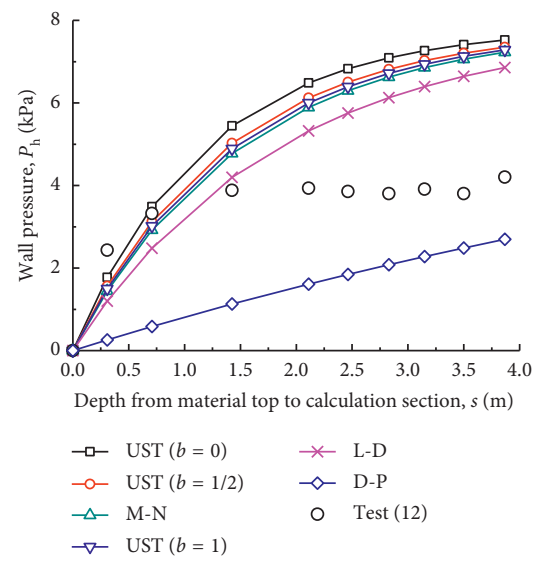

(f)

Figure 3: Comparisons of the results from six strength criteria with experimental data for deep silos. (a) Experimental data with coal from Liu and Hao [7]. (b) Experimental data with wheat from Liu and Hao [7]. (c) Experimental data with dry sand from Liu and Hao [7]. (d) Experimental data with standard sand from Zhang et al. [8]. (e) Experimental data with wheat from Ruiz et al. [11]. (f) Experimental data with dry sand from Munch-Andersen et al. [12].

criterion). The results of the UST ( $b=0$, i.e., the M-C criterion) are consistent with those of the Chinese silo standard. The experimental data are basically distributed in the region between the results from the UST $(b=0)$ and the D-P criterion. All this means that, overall, the effect of the intermediate stress should be considered accurately to calculate the wall pressure for deep silos.

4.2. Squat Silos. Yuan [13] carried out several field tests to measure the wall pressure distribution of squat silos (No. 4, No. 7, and No. 8) from Xuzhou National Grain Reserve.
Chen [14] carried out similar field tests to measure the wall pressure distribution of squat silos (No. 4) from Henan National Grain Reserve. In this case, the stored height $h$ of bulk solids is considered to be the silo height $H$, and then $h / D<1.5$. The geometric data and material properties are presented in Table 2.

Due to similar variations of the wall pressure for different stored heights, only some field experimental data from Yuan [13] (No. 4 and No. 7 silos for the first and second groups, as well as No. 8 silo for the first group) and from Chen [14] (No. 4 silo for the first group) are adopted to make the following comparisons. 


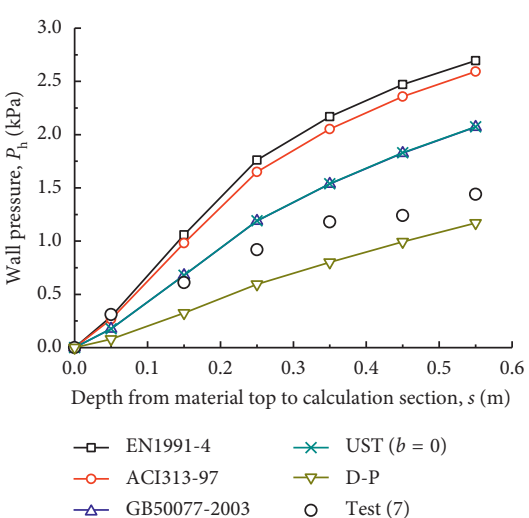

(a)

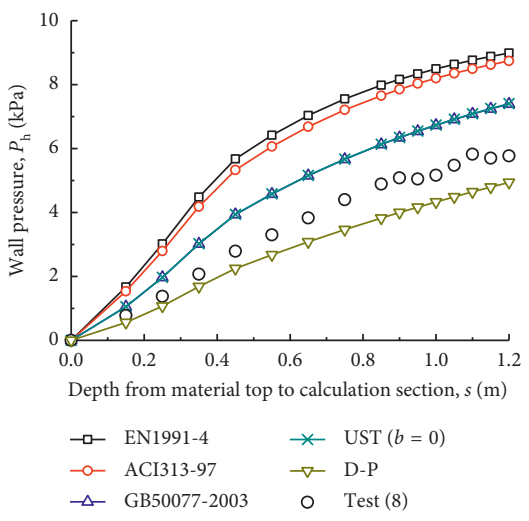

(d)

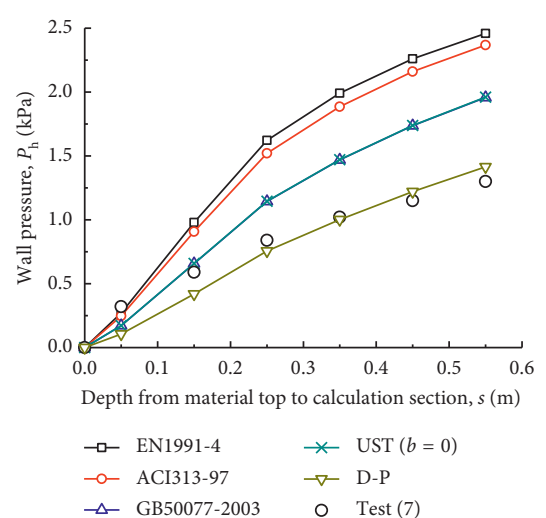

(b)

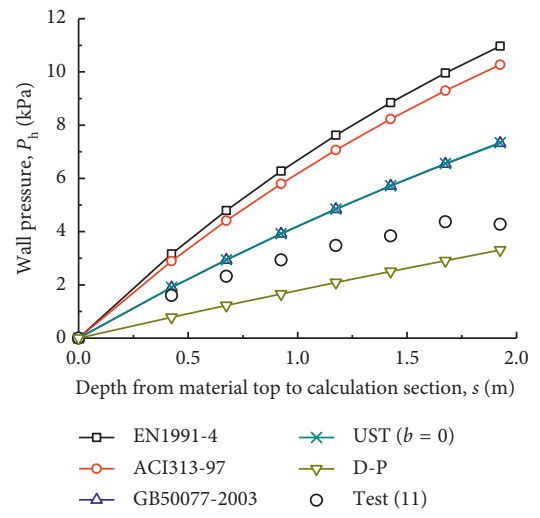

(e)

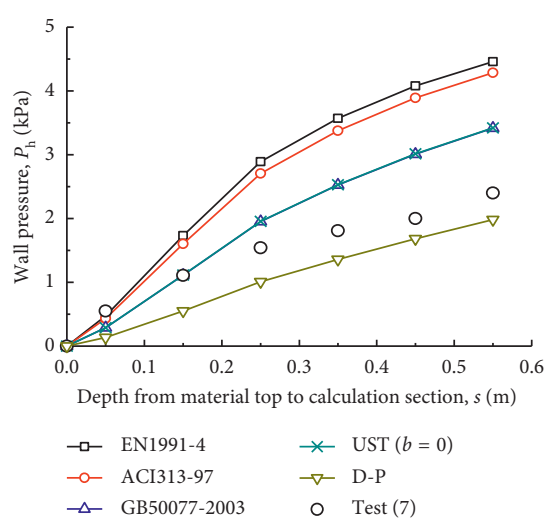

(c)

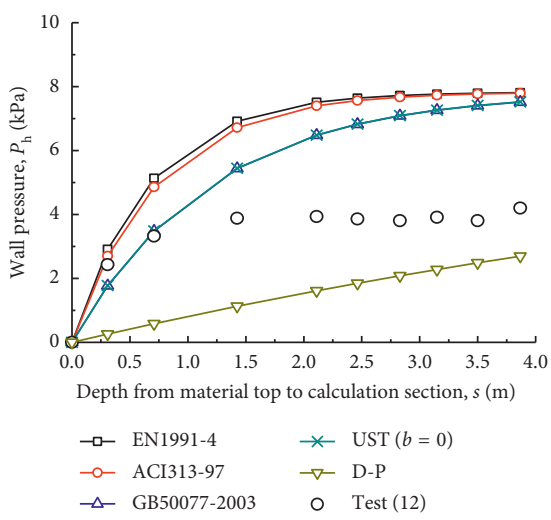

(f)

Figure 4: Comparisons of the results from three standards and two strength criteria with experimental data for deep silos. (a) Experimental data with coal from Liu and Hao [7]. (b) Experimental data with wheat from Liu and Hao [7]. (c) Experimental data with dry sand from Liu and Hao [7]. (d) Experimental data with standard sand from Zhang et al. [8]. (e) Experimental data with wheat from Ruiz et al. [11]. (f) Experimental data with dry sand from Munch-Andersen et al. [12].

4.2.1. Comparisons of the Results from Different Criteria. Figure 5 compares the six sets of experimental data with the results from six strength criteria for squat silos. For both cone piles and flat piles, the differences of the wall pressure for squat silos using different strength criteria are found to be significant. The values of the wall pressure corresponding to the six strength criteria are the UST $(b=0)>$ the UST $(b=1 / 2) \approx$ the M-N criterion $>$ the UST $(b=1)>$ the L-D criterion $>$ the D-P criterion. This scale is the same as that for deep silos.

For all six groups of field tests, the average ratios of the $P_{\mathrm{h}}$ using these six strength criteria to the experimental data are (from larger to smaller) 1.21, 1.09, 1.07, 1.01, 1.00, and 0.82 . It is demonstrated that the $P_{\mathrm{h}}$ based on the UST when $b=0$ (i.e., the M-C criterion) is the largest; the $P_{\mathrm{h}}$ based on the UST when $b=1 / 2$ is also close to that based on the M-N criterion; the $P_{\mathrm{h}}$ using the UST when $b=1$ is close to that using the L-D criterion. Furthermore, the $P_{\mathrm{h}}$ on the basis of the L-D criterion is shown to be very consistent with the experimental data for the average ratio being 1.00 .

4.2.2. Comparisons of the Results from the Theories. For squat silos, all standards make use of the same formulation expressed in Equation (2) to calculate the wall pressure. There are two classical theories, which have been adopted by different standards, to determine the wall pressure coefficient $k[32,33]$. One is the Rankine theory. The other is the modified Coulomb theory.

Figure 6 presents the six sets of experimental data for squat silos that are now once again compared with the $P_{\mathrm{h}}$ calculated by the Rankine theory, the modified Coulomb theory and the UST $(b=0)$ in which the intermediate stress effect is null, as well as the D-P criterion in which the intermediate stress effect is the greatest. The $P_{\mathrm{h}}$ calculated by the two theories and the two strength criteria are as follows (from larger to smaller): the modified Coulomb theory $>$ the Rankine theory $=$ the UST $(b=0)>$ the D-P criterion. For the six groups of field tests, the average ratios of the $P_{\mathrm{h}}$ using the two theories and the two strength criteria to the experimental data are (from larger to smaller) 1.56, 1.21, 1.21, and 0.82 .

From the above results, it is demonstrated that the Rankine theory and the modified Coulomb theory are more conservative than the strength criterion considering the intermediate stress effect (i.e., the D-P criterion). The results of the UST when $b=0$ (i.e., the M-C criterion) are the same as those of the Rankine theory. The experimental data are also generally located in the region between the results from 
TABLE 2: Geometrical data and material properties of squat silos.

\begin{tabular}{|c|c|c|c|c|c|c|c|c|c|}
\hline References & Test location & Silo number & $h(\mathrm{~m})$ & Pile type & $D(\mathrm{~m})$ & Bulk solids & $\gamma\left(\mathrm{kN} / \mathrm{m}^{3}\right)$ & $\varphi\left(^{\circ}\right)$ & $\delta\left(^{\circ}\right)$ \\
\hline Yuan [13] & Xuzhou National Grain Reserve & $\begin{array}{l}\text { No. } 4 \\
\text { No. } 4 \\
\text { No. } 7 \\
\text { No. } 7 \\
\text { No. } 8\end{array}$ & $\begin{array}{c}13.43 \\
13.71 \\
9.93 \\
13.77 \\
6.35 \\
\end{array}$ & $\begin{array}{l}\text { Cone } \\
\text { Flat } \\
\text { Cone } \\
\text { Flat } \\
\text { Cone }\end{array}$ & 15 & Wheat & 7.88 & 25 & 21.8 \\
\hline Chen [14] & Henan National Grain Reserve & No. 4 & 7.30 & Cone & 26 & Wheat & 8.22 & 25 & 21.8 \\
\hline
\end{tabular}

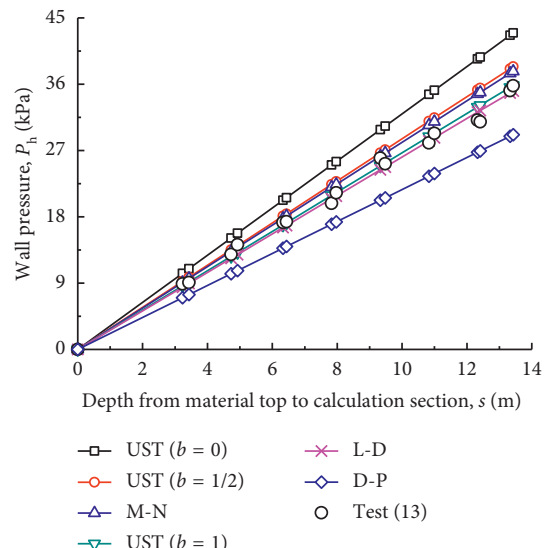

(a)

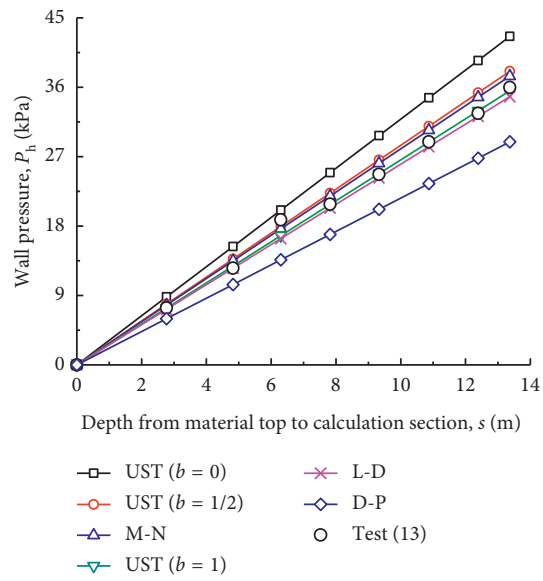

(d)

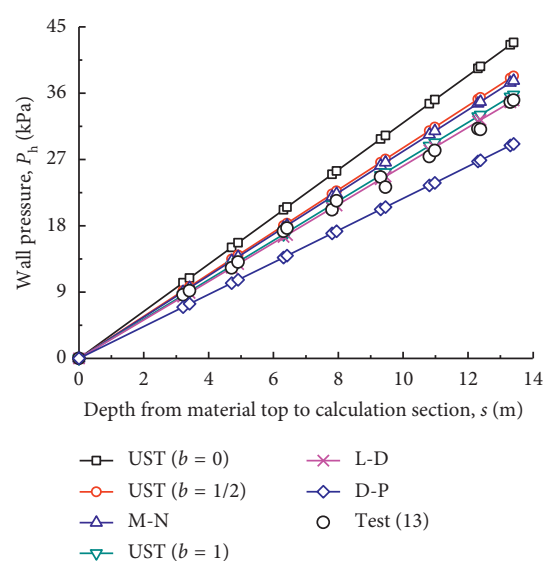

(b)

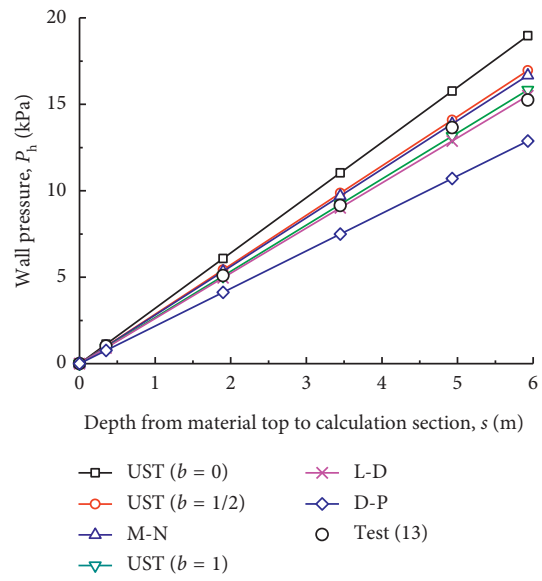

(e)

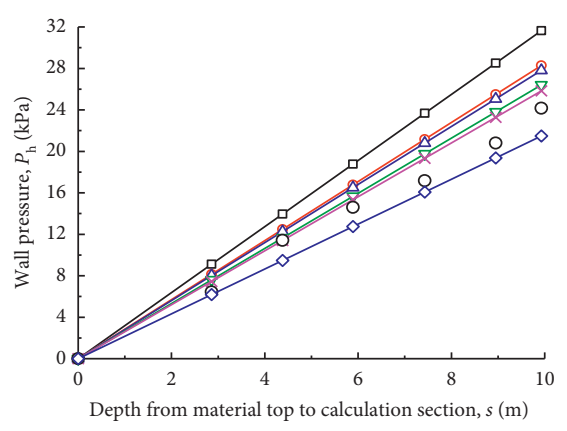

$$
\begin{aligned}
& \rightarrow-\text { UST }(b=0) \quad * \text { L-D } \\
& \text {-o- UST }(b=1 / 2) \\
& \triangle-\mathrm{M}-\mathrm{N} \\
& \text { ○ Test (13) }
\end{aligned}
$$

(c)

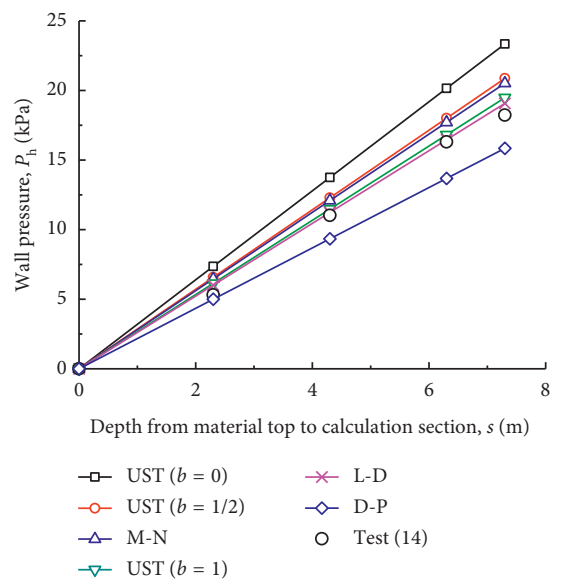

(f)

Figure 5: Comparisons of the results from six strength criteria with experimental data for squat silos (modified from Sun et al. [37]). (a) Experimental data of No. 4 silo for the first group from Yuan [13] (cone pile). (b) Experimental data of No. 4 silo for the second group from Yuan [13] (flat pile). (c) Experimental data of No. 7 silo for the first group from Yuan [13] (cone pile). (d) Experimental data of No. 7 silo for the second group from Yuan [13] (flat pile). (e) Experimental data of No. 8 silo for the first group from Yuan [13] (flat pile). (f) Experimental data of No. 4 silo for the first group from Chen [14] (cone pile).

the UST $(b=0)$ and the D-P criterion. This ordering is a clear indication that the wall pressure for squat silos is not accurately calculated if the intermediate stress effect is not considered rationally.

\section{Conclusions}

Through this study, some primary conclusions can be drawn as follows:
(1) Based on the principles and basic assumptions of silo wall pressure, four novel wall pressure coefficients are presented for the D-P criterion, the M-N criterion, the L-D criterion, and the UST to consider the effect of the intermediate stress. For the D-P criterion, the internal friction angle of bulk solids cannot be greater than $42.22^{\circ}$, whereas the other three strength criteria are not restricted. These four coefficients are readily used to predict the wall pressure 


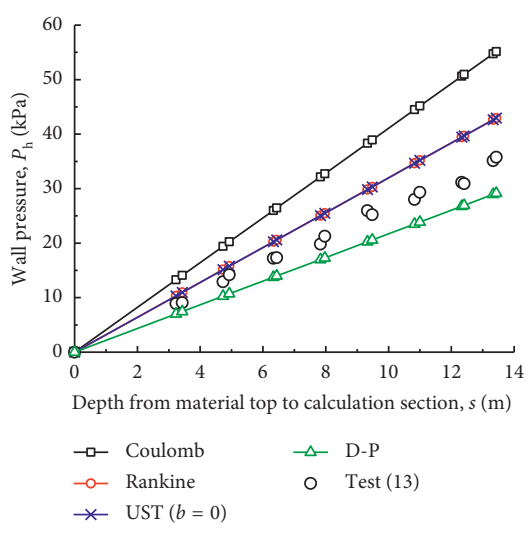

(a)

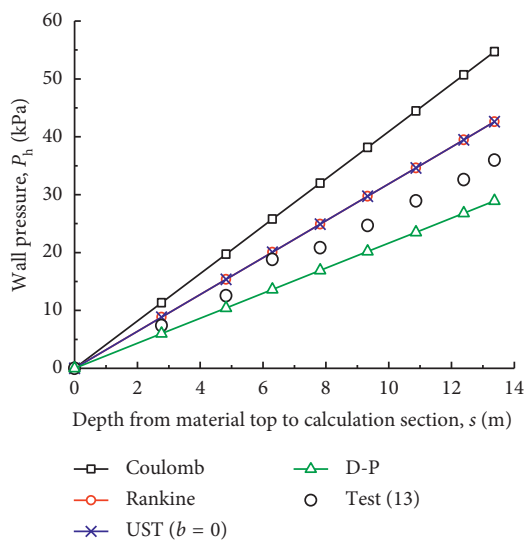

(d)

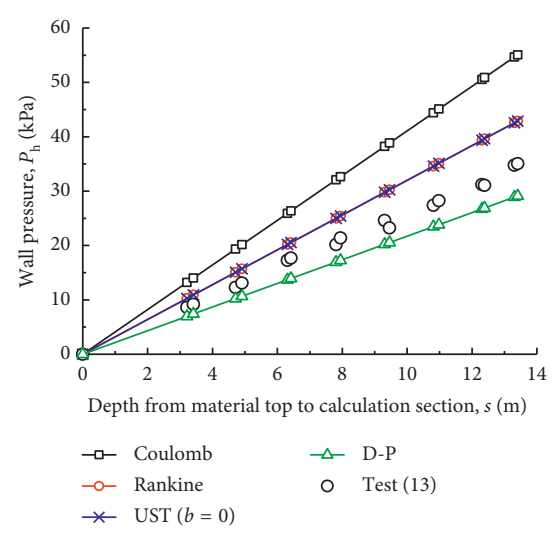

(b)

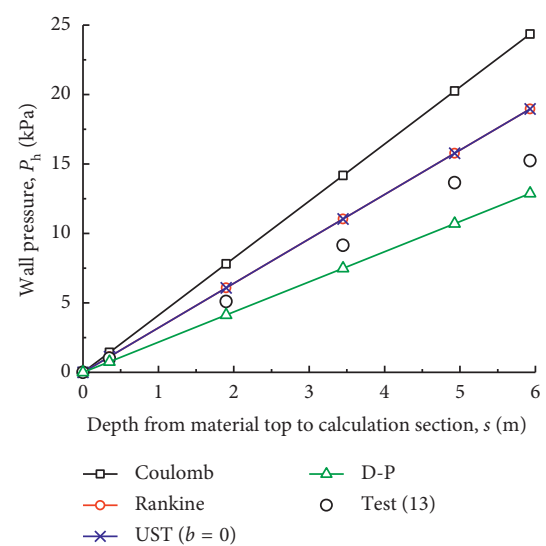

(e)

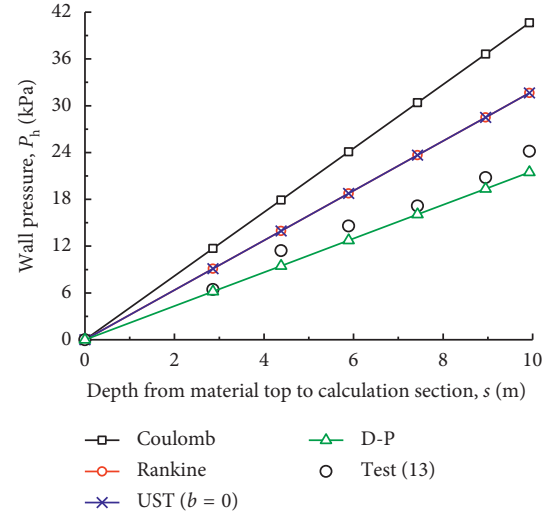

(c)

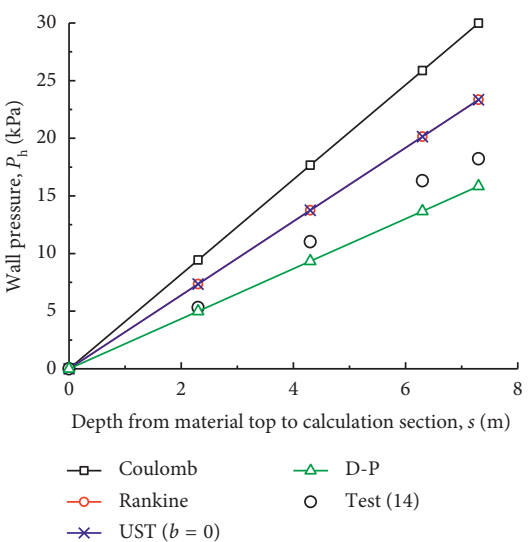

(f)

FIGURE 6: Comparisons of the results from two theories and two strength criteria with experimental data for squat silos (modified from Sun et al. [37]). (a) Experimental data of No. 4 silo for the first group from Yuan [13] (cone pile). (b) Experimental data of No. 4 silo for the second group from Yuan [13] (flat pile). (c) Experimental data of No. 7 silo for the first group from Yuan [13] (cone pile). (d) Experimental data of No. 7 silo for the second group from Yuan [13] (flat pile). (e) Experimental data of No. 8 silo for the first group from Yuan [13] (flat pile). (f) Experimental data of No. 4 silo for the first group from Chen [14] (cone pile).

for both deep and squat silos, and their predictions are compared with several sets of experimental data and the results from three national standards as well as two theories.

(2) For the wall pressure of deep silos, the European standard is the most conservative one, followed by the American one. The results of the Chinese standard are the same as those of the UST when $b=0$; the results of the UST when $b=1 / 2$ are close to that of the $\mathrm{M}-\mathrm{N}$ criterion. For the wall pressure of squat silos, the modified Coulomb theory is the most conservative. The results of the Rankine theory are equal to those of the UST when $b=0$; the results of the UST when $b=1 / 2$ are also close to that of the M-N criterion; the results from the UST when $b=1$ and the L-D criterion are nearly equivalent.

(3) The effect of strength criterion on the wall pressure for both deep and squat silos is found to be very significant. It is indicated that the intermediate stress effect is in fact dealt with distinctly by the different strength criteria. The wall pressure using the UST when $b=0$ is overestimated since it does not consider the intermediate stress effect. On the contrary, the wall pressure based on the D-P criterion is underestimated due to the overestimation on this criterion of the effect of the intermediate stress. Overall, the wall pressure generated by the L-D criterion agrees well with the experimental data due to rational consideration that it makes use of the intermediate stress effect. Accordingly, the L-D criterion is recommended to be adopted to calculate the silo wall pressure.

\section{Data Availability}

The data used to support the findings of this study are available from the corresponding author upon request.

\section{Conflicts of Interest}

The authors declare that there are no conflicts of interest regarding the publication of this paper. 


\section{Acknowledgments}

The financial support provided by the Natural Science Foundation of China (Grant nos. 51708035 and 51878056), the Fundamental Research Fund for the Central Universities (Grant nos. 310828173402, 310828171012, 300102288109, and 310828171003), and the Research Fund for the Doctoral Program of Higher Education (Grant no. 20110205130001) is gratefully acknowledged.

\section{References}

[1] H. A. Janssen, "Versuch uber getreidedruck in sillozellen," Zeitschrift des Vereins Deutscher Ingenieure, vol. 39, no. 35, pp. 1045-1049, 1895.

[2] M. L. Reimbert and A. M. Reimbert, "Silos, theory and practice," Journal of Thought, vol. 5, no. 3, pp. 141-156, 1976.

[3] G. Abdelsayed and F. Monasa, "Cold-formed steel farm structures part I: grain bins," Journal of Structural Engineering, vol. 111, no. 10, pp. 2065-2089, 1985.

[4] J. Y. Ooi, Bulk solid behavior and silo wall pressure, Ph.D. thesis, University of Sydney, Sydney, Australia, 1990.

[5] Z. Zhong, J. Y. Ooi, and J. M. Rotter, "The sensitivity of silo flow and wall stresses to filling method," Engineering Structures, vol. 23, no. 7, pp. 756-767, 2001.

[6] J. B. Fu, Lateral wall pressure analysis and three-dimensional foundation consolidation analysis of large diameter silo, Ph.D. thesis, Dalian University of Technology, Dalian, China, 2012.

[7] D. H. Liu and J. P. Hao, "Study on wall pressure of RC silo," Journal of Building Structures, vol. 16, no. 5, pp. 57-63, 1995.

[8] D. Y. Zhang, Q. K. Xu, S. M. Wang, and X. P. Liang, "Simulation and experimental validation of silo wall pressure during discharge," Transactions of the Chinese Society of Agricultural Engineering, vol. 33, no. 5, pp. 272-278, 2017.

[9] C. J. Brown, E. H. Lahlouh, and J. M. Rotter, "Experiment on a square planform steel silo," Chemical Engineering Science, vol. 55, no. 20, pp. 4399-4413, 2000.

[10] A. Couto, A. Ruiz, and P. J. Aguado, "Design and instrumentation of a mid-size test station for measuring static and dynamic pressures in silos under different conditionspart I: description," Computers and Electronics in Agriculture, vol. 85, pp. 164-173, 2012.

[11] A. Ruiz, A. Couto, and P. J. Aguado, "Design and instrumentation of a mid-size test station for measuring static and dynamic pressures in silos under different conditionspart II: construction and validation," Computers and Electronics in Agriculture, vol. 85, pp. 174-187, 2012.

[12] J. Munch-Andersen, V. Askegaard, and A. Brink, Silo Model Tests with Sand, SBI Bulletins No. 91, Danish Building Research Institute, Hørsholm, Denmark, 1992.

[13] F. Yuan, Analysis of bulk-solid pressure on curve walls and its engineering application, Ph.D. thesis, Dalian University of Technology, Dalian, China, 2004.

[14] C. B. Chen, Bulk-solid pressures on silos' walls, Ph.D. thesis, Hefei University of Technology, Hefei, China, 2006.

[15] J. Y. Ooi and J. M. Rotter, "Wall pressure in squat steel silo from simple finite element analysis," Computers and Structures, vol. 37, no. 4, pp. 361-374, 1990.

[16] J. F. Chen, J. M. Rotter, and J. Y. Ooi, "A review of numerical prediction methods for silo wall pressures," Advances in Structural Engineering, vol. 2, no. 2, pp. 119-135, 1999.

[17] M. A. Martinez, I. Alfaro, and M. Doblare, "Simulation of axisymmetric discharging in metallic silos. Analysis of the induced pressure distribution and comparison with different standards," Engineering Structure, vol. 24, no. 12, pp. 15611574, 2002.

[18] Y. Wang, Y. Lu, and J. Y. Ooi, "Finite element modeling of wall pressures in a cylindrical silo with conical hopper using an Arbitrary Lagrangian-Eulerian formulation," Powder Technology, vol. 257, no. 5, pp. 181-190, 2014.

[19] Y. Wang, Y. Lu, and J. Y. Ooi, "A numerical study of wall pressure and granular flow in a flat-bottomed silo," Powder Technology, vol. 282, no. 24, pp. 43-54, 2015.

[20] J. Horabik, P. Parafiniuk, and M. Molenda, "Experiments and discrete element method simulation of distribution of static load of grain bedding at bottom of shallow model silo," Biosystems Engineering, vol. 149, pp. 60-71, 2016.

[21] F. Ayuga, Some Unresolved Problems in the Design of Steel Cylindrical Silos, CRC Press-Taylor Francis Group, Boca Raton, FL, USA, 2008.

[22] A. Dogangun, Z. Karaca, A. Durmus, and H. Sezen, "Cause of damage and failures in silo structures," Journal of Performance of Constructed Facilities, vol. 23, no. 2, pp. 65-71, 2009.

[23] A. Jansseune, W. D. Corte, and J. Belis, "Elastic failure of locally supported silos with U-shaped longitudinal stiffeners," KSCE Journal of Civil Engineering, vol. 19, no. 4, pp. 10411049, 2015.

[24] P. C. Arnold, A. G. Mclean, and A. W. Robert, Bulk Solids: Storage, Flow and Handling, Tunra Bulk Solids Handling Research Associates, University of Newcastle, Callaghan, NSW, Australia, 1980.

[25] A. G. Bishara, Interaction of Bin and Stored Bulk Solids, Design of Steel Bins for the Storage of Bulk Solids, University of Sydney, Sydney, Australia, 1895.

[26] E. H. Gaylord and C. N. Gaylord, Design of Steel Bins for Storage of Bulk Solids, Prentice Hall, Englewood Cliffs, NJ, USA, 1984.

[27] GB50077-2003, Code for Design of Reinforced Concrete Silos, National Standards Compilation Group of Peoples' Republic of China, Beijing, China, 2003.

[28] ACI313-97, Standard Practice for Design and Construction of Concrete Silos and Stacking Tubes for Storing Granular Materials, American Concrete Institute, Indianapolis, MI, USA, 1997.

[29] EN1998-4-2007, Eurocode 8 Design of Structure for Earthquake Resistance. Part 4: Silos, Tanks and Pipelines, European Committee for Standardization, 2007.

[30] DIN1055, Design Loads for Buildings: Loads in Silo Bins, Deutsches Institut fur Normung, Berlin, Germany, 1987.

[31] AS3774-1996, Loads on Bulk Solids Containers, Standard Association of Australia, Sydney, Australia, 1996.

[32] W. J. M. Rankine, "On the stability of loose earth," Philosophical Transactions of the Royal Society of London, vol. 147, pp. 9-27, 1857.

[33] C. A. Coulomb, Essai sur une Application des Regles de Maximis et Minimis a Quelques Problems de Statique Relatifs a la Architecture, 1973.

[34] S. Q. Xu and M. H. Yu, "The effect of the intermediate principal stress on the ground response of the circular openings in rock mass," Rock Mechanics and Rock Engineering, vol. 39, no. 2, pp. 169-181, 2006.

[35] S. S. Sun, J. H. Zhao, C. G. Zhang, and Y. Cui, "Wall pressure of large squat silos based on the unified strength theory," Engineering Mechanics, vol. 30, no. 5, pp. 244-249, 2013.

[36] S. S. Sun, J. H. Zhao, C. G. Zhang, and K. Yang, "New solution for lateral pressure of silos and bunkers," Journal of Guangxi University, vol. 43, no. 1, pp. 168-177, 2018. 
[37] S. S. Sun, J. H. Zhao, and C. G. Zhang, "Lateral pressure calculation for silos considering intermediate principal stress effect," Journal of Architecture and Civil Engineering, vol. 35, no. 3, pp. 71-78, 2018.

[38] J. L. Shang, Y. L. Gui, and Z. Y. Zhao, "Broad-spectrum fracture toughness of an anisotropic sandstone under mixedmode loading," Theoretical and Applied Fracture Mechanics, vol. 96, pp. 556-575, 2018.

[39] L. R. Alejano, "Drucker-Prager criterion," Rock Mechanics and Rock Engineering, vol. 45, no. 6, pp. 995-999, 2012.

[40] H. Jiang and Y. L. Xie, "A note on the Mohr-Coulomb and Drucker-Prager strength criterion," Mechanics Research Communication, vol. 38, no. 4, pp. 309-314, 2011.

[41] M. C. Liu, Y. F. Gao, and H. L. Liu, "A nonlinear DruckerPrager and Matsuoka-Nakai unified failure criterion for geomaterials with separated stress invariant," International Journal of Rock Mechanics and Mining Sciences, vol. 50, no. 2, pp. 1-10, 2012.

[42] C. G. Zhang, Q. Yan, and C. L. Zhang, "A unified solution of critical filling height for embankment considering intermediate principal stress and its comparisons," Chinese Journal of Rock Mechanics and Engineering, vol. 35, no. 7, pp. 1466-1473, 2016.

[43] L. Q. Guo, Q. P. Cai, and X. Q. Peng, "Effect of strength criterion on design of strip coal pillar," Rock and Soil Mechanics, vol. 35, no. 3, pp. 777-782, 2014.

[44] H. Jiang, "Expressing strength criterion in principal stress plane base on equivalent Mohr-Coulomb friction angle," Journal of Central South University (Science and Technology), vol. 43, no. 8, pp. 3216-3221, 2012.

[45] M. H. Yu, Twin Shear Theory and Its Application, Science Press, Beijing, China, 1998. 


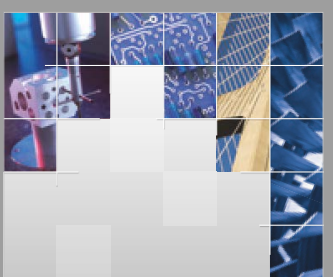

\section{Enfincering}
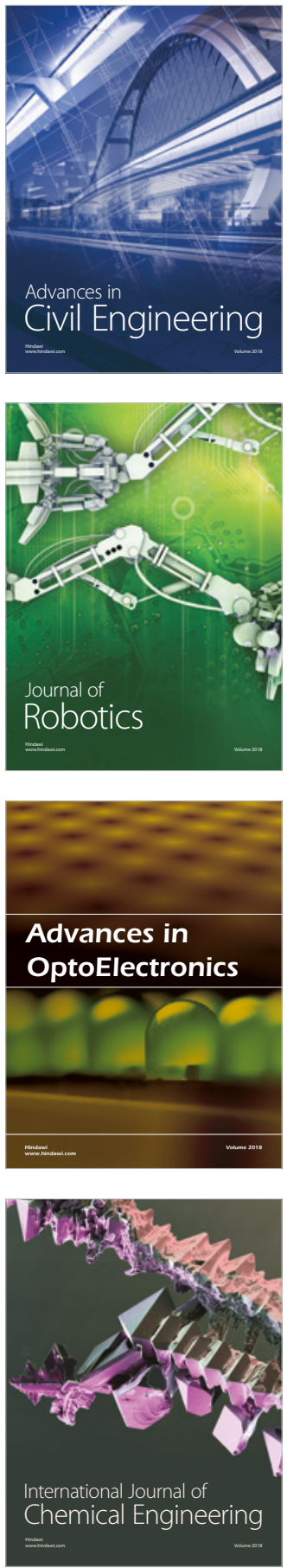

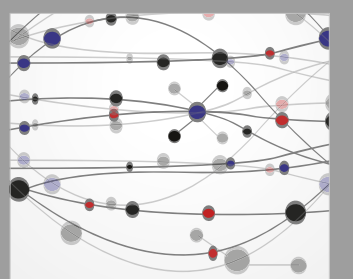

\section{Rotating \\ Machinery}

The Scientific World Journal

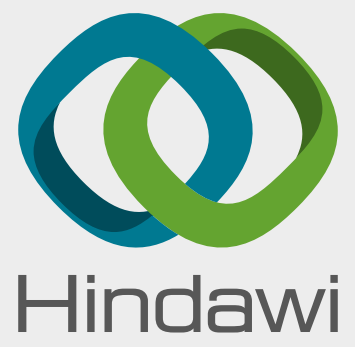

Submit your manuscripts at

www.hindawi.com
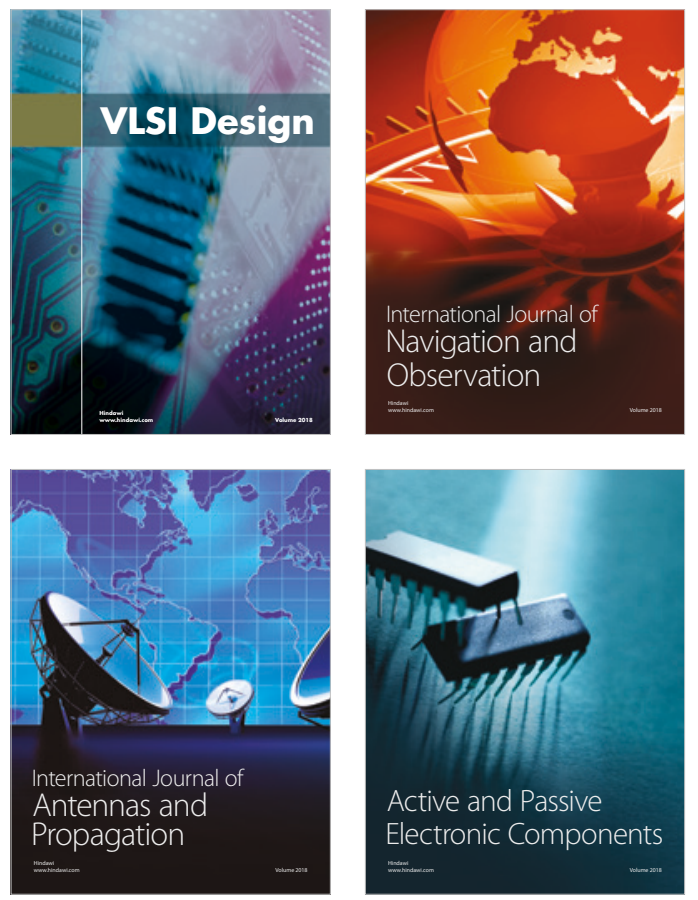
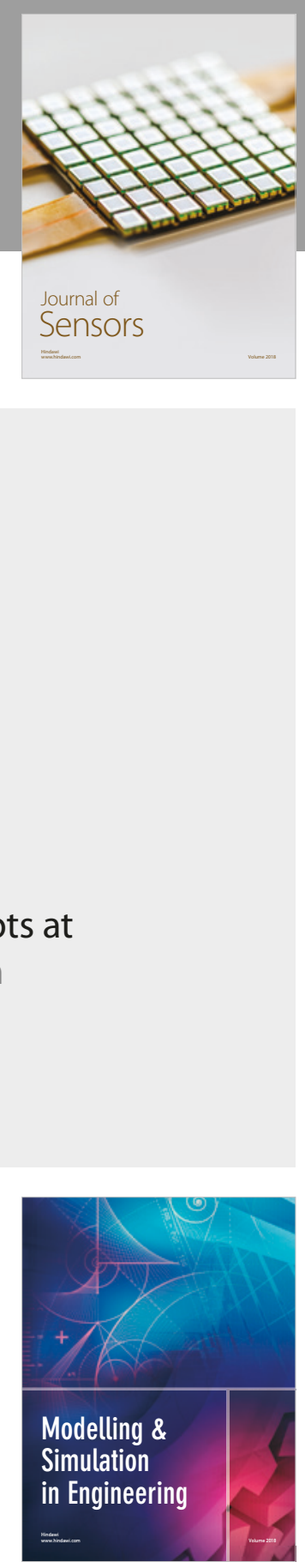

\section{Advances \\ Multimedia}
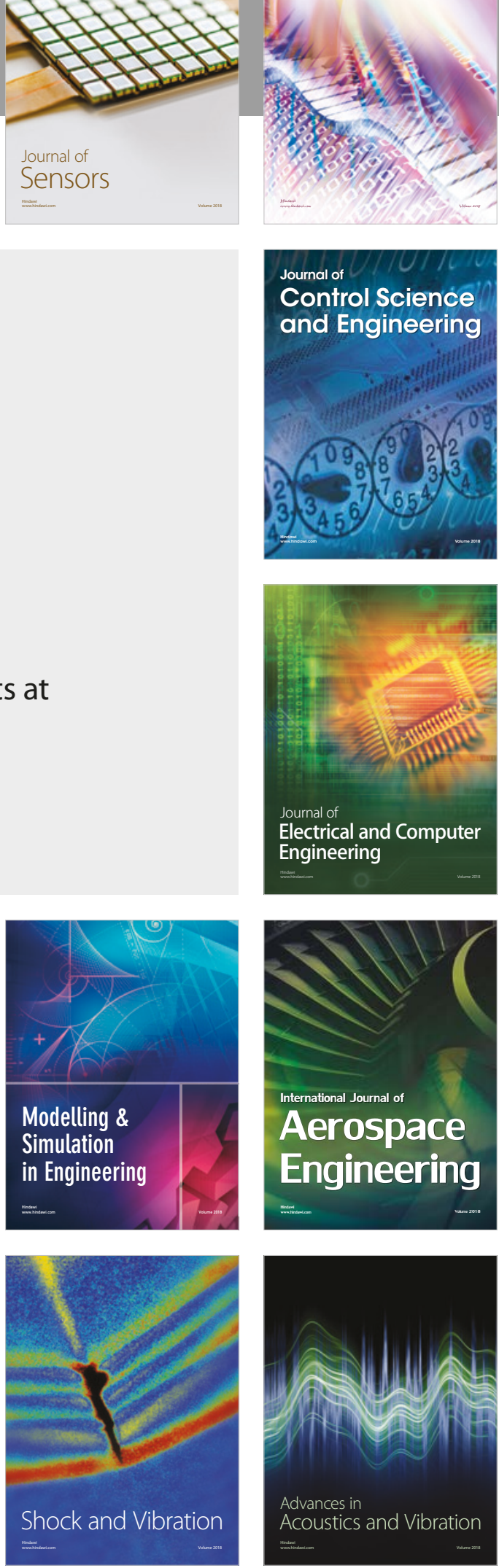